\title{
Diagnóstico da implantação da Metodologia de Gestão Estratégica World Class Manufacturing (WCM) nas indústrias de Pernambuco
}

Title: Diagnosis of the implementation of strategic management World Class Manufacturing methodology (WCM) in Pernambuco industries

Isabel Siega Freitas

Escola Politécnica de Pernambuco

Universidade de Pernambuco

50.720-001 - Recife, Brasil

Bel_freitas87@hotmail.com

\author{
Luis Cordeiro de Barros Filho \\ Escola Politécnica de Pernambuco \\ Universidade de Pernambuco \\ 50.720-001 - Recife, Brasil \\ lbarros27@gmail.com
}

Resumo A metodologia do World Class Manufacturing (WCM) ou Manufatura de Classe Mundial surge como um novo modelo de gestão da excelência empresarial eficaz, eficiente e efetivo. Este Modelo é um conjunto de práticas, conceitos, princípios, políticas e técnicas baseadas nos princípios da Produção Enxuta para a gestão por processos de uma organização. O presente trabalho tem como proposta principal identificar o nível de utilização das Práticas de Gestão do WCM em empresas no Estado de Pernambuco, Brasil. Baseado nos resultados da aplicação da pesquisa de campo foram formuladas as conclusões que mostram os pontos fortes e a baixa utilização destas práticas de Gestão do WCM e consequentemente identificando-se oportunidades de melhoria para estas Organizações pesquisadas e consequentemente as que querem aderir a este Modelo de Gestão de Classe Mundial.

Palavras-Chave: World Class Manufacturing (WCM), Pernambuco, Classe mundial, Modelo de Gestão, Produção Enxuta

\begin{abstract}
The World Class Manufacturing (WCM) methodology emerges as a new model of effective, efficient and effective management of business excellence. This model is a set of practices, concepts, principles, policies and techniques based on the principles of Lean Production for the management by processes of an organization. The main objective of this paper is to identify the level of use of the Management Practices of WCM in companies in the State of Pernambuco, Brazil. Based on the results of the applied field research, the conclusions were drawn that show the strengths and the low utilization of these practices of WCM Management and consequently identifying opportunities for improvement for these Organizations researched and consequently those who want to join this World Class Management Model.
\end{abstract}

Keywords: World Class Manufacturing (WCM), World Class, Management Model, Lean Production 


\section{Introdução}

Com o processo de globalização da economia criando uma competitividade mundial nos mercados, as empresas passaram a buscar meios de fortalecimento para garantir sua sobrevivência em tempos de escassez ou sua prosperidade em tempos de oportunidades, somente desta forma pode-se manter a sustentabilidade empresarial pra permitir a perpetuação de seus negócios. Com isto está sempre à frente de seus concorrentes, significa estar preparado e apto a lidar com as constantes mudanças do mercado. Segundo Slack et al.(2002), para alguns gestores, a qualidade é o mais importante fator singular que afeta o desempenho de uma organização em relação a seus concorrentes. Nos dias de hoje tornou-se um grande diferencial competitivo entre as empresas investir continuamente em melhorias tanto na qualidade do produto quanto na qualidade do processo e da gestão. Por isso todo o processo produtivo sempre poderá ser melhorado não importando se foram devidamente projetados, se estão bem gerenciados e controlados. (Slack et al., 2002).

Segundo Ohno (1997), não existe um método que garanta a sobrevivência no mercado atual, mas sim a necessidade de um Sistema de Gestão Total que desenvolva habilidades humanas até sua mais plena capacidade, afim de melhor realçar a criatividade e a operosidade, para se utilizar bem instalações e máquinas, e eliminar todo o desperdício.

O World Class Manufacturing (WCM) é Modelo de Gestão que vem ganhando cada vez mais espaço e credibilidade no ambiente industrial por apresentar casos de sucesso em várias empresas de classe mundial. Seus objetivos são: reunir as melhores práticas de gestão, ferramentas e conceitos de manufatura e criar a melhor interação e integração possível entre as áreas, as quais são vistas como pilares técnicos, buscando a redução contínua de perdas para alcançar "zero quebras", "zero desperdícios", "zero estoques" e "zero defeitos" através de um pensamento enxuto na manufatura. Em resumo, o pensamento enxuto é uma forma de fazer cada vez mais com cada vez menos - menos esforço humano, menos equipamentos, menos tempo e menos espaço (WOMACK; JONES, 2006).

A Manufatura de Classe Mundial ou World Class Manufacturing (WCM), conceito originalmente introduzido por Hayes and Wheelwright (1984), caracteriza-se como um Modelo de Gestão abrangente que busca garantir a excelência da gestão, de processo e de produtos pela redução das perdas de forma intensa e diferenciada, por meio de equipes de alto desempenho. É caracterizada, entre outras coisas, por se superar nos quesitos qualidade e tecnologia (WIREMAN, 1990; CHIAVENATO, 1993), indo na direção da Excelência empresarial.
Este novo modo de gerir a produção de uma empresa, criada em 2005 pelo professor emérito da Universidade de Kyoto e, hoje, auditor e certificador da metodologia nas diversas plantas ao redor do mundo, Hajime Yamashina que visa melhorar a desempenho de seus processos de logística, de qualidade, de manutenção, de custos, etc., através de métodos e conceitos de manufatura a nível de Classe Mundial.

Alguns dos benefícios de integrar o World Class Manufacturing (WCM) e seus conceitos no modo de produzir determinado bem ou serviço incluem o aumento da competitividade, desenvolvimento de novas tecnologias, maior flexibilidade, melhor comunicação entre gestão e produção e aumento da qualidade do trabalho (FELICE; PETRILLO; MONFREDA, 2013).

\section{Objetivos}

Este trabalho tem com objetivo geral: Elaborar um diagnóstico da implantação das práticas de Gestão da WCM no Estado de Pernambuco.

Os seguintes objetivos específicos foram determinados e executados: pesquisa bibliográfica, em que foram identificados os principais componentes do World Class Manufacturing (WCM); elaboração de questionário, contemplando as práticas de gestão do WCM e adicionais; pesquisa de campo, por meio de entrevista, utilizando um formulário de pesquisa, ou seja, questionário; A estratificação dos resultados e identificação dos pontos fortes e oportunidades de melhorias; com análise de resultados e orientações.

\section{Fudamentação Teórica}

O (WCM) é um conjunto de conceitos, princí-pios, políticas e técnicas baseadas nos princípios da pro-dução enxuta para a gestão dos processos operacionais de uma empresa (PASSARELLA, 2007).

O WCM é um método de gestão que indica e elimina as perdas existentes nos processos produtivos e administrativos, maximiza o uso do ativo industrial e garante a geração de produtos de alta qualidade a custos competitivos. Além disso, desenvolve conhecimentos capazes de reeducar as pessoas para ações de prevenção e de melhoria contínua, garantindo o aumento da confiabilidade dos equipamentos e da capabilidade dos processos, sem grandes investimentos adicionais.

Do ponto de vista de implementação, o WCM possui os próprios métodos, conceitos e ferramentas que possibilitam organizações alcançar vantagem competiti-va, através de uma manufatura da mais alta qualidade a preços baixos (PALUCHA, 2012). 
Segundo Schonberger (1986), muitas empresas vêm utilizando um conjunto de estratégias conhecidas como World Class Manufacturing, como fundamento para as suas estratégias de manufatura, conduzindo a um ótimo desempenho e ganhando competitividade.

Paddock (1993) apresenta o termo "Fabricação de Classe Mundial" (WCM) como aquele usado para descrever os melhores fabricantes do mundo. Segundo a autora estas empresas passaram a enxergar a importância da manufatura como arma estratégica. Rubrich (2004) assegura que o princípio WCM deve ser difundido em toda fábrica, com o comprometimento do gerente ao operador, sendo uma filosofia Top-Down (de cima para baixo). O WCM quebra a rotina da fábrica estabelecendo uma nova forma de trabalho, pois apresenta ênfase na eliminação de refugo, aumento de qualidade, satisfação do cliente e aumento da produtividade. Yamashina (2007) define WCM como o nível de excelência de todo o ciclo logístico - produtivo, tratando das metodologias aplicadas e do desempenho alcançado pelas melhores organizações mundiais. De acordo com o autor o WCM se baseia nos conceitos de: Total Productive Maintenance (TPM); Total Quality Control (TQC); Total Industrial Engineering (TIE); Just In Time (JIT);

Segundo Martins (2005), Total Productive Maintenance (TPM), Manutenção Produtiva Total, é muito mais do que fazer somente manutenção. É uma filosofia gerencial que atua na forma de como agir em uma organização, no comportamento das pessoas e os problemas ligados ao processo produtivo. A TPM visa atingir o zero quebra ou falha, com três princípios fundamentais:

- Melhoria das pessoas, pois todo programa começa com o treinamento.

- Melhoria dos equipamentos, pois todos os equipamentos devem ser melhorados para obter grandes ganhos de produtividade.
- E qualidade total, pois a criação de um programa de TPM deve caminhar junto com um programa de Controle da Qualidade Total (TQC).

Segundo Rubrich (2004), o TQC ou Controle da Qualidade Total, argumenta que a responsabilidade deve ficar nas mãos de quem executa o trabalho, de forma que todos os operadores recebem autoridade de parar uma linha de produção sempre que ocorrer um problema com qualidade. Cuidando mais do processo (atitude pró-ativa) ao invés de gerenciar o produto já transformado (atitude passiva), visando o zero defeito, o TQC junto ao Total Industrial Engineering (TIE), trabalham na eliminação dos erros para evitar o desperdício.

Segundo Paddock (1993), o TIE (Total Industrial Engineering), Engenharia Industrial Total é uma abordagem integrada dos problemas da produção, buscando a melhoria contínua dos processos produtivos e a eliminação de todas as formas de desperdício através do envolvimento das pessoas que compõe a fábrica. Gaitear (2002), diz que o Just in Time (JIT), no momento certo visa o zero estoque, reduzindo todos os estoques de produtos em processo ao longo da cadeia produtiva, reduzindo o lead time de manufatura, que é o tempo transcorrido entre o ponto de pedido de um cliente até o ponto de recebimento do produto. O JIT controla o abastecimento para que aconteça exatamente quando solicitado e seja entregue no exato momento em que foi requerido. O resultado é um fluxo uniforme, ininterrupto com pequenos lotes de produtos, evitando gerar estoque, escassez ou desperdício.

Segundo Paddock (1993), a implementação do WCM se entendido e acompanhado pela gerência, pode mudar a personalidade da fábrica, ou cultura de uma organização. Yamashina (2007) apresenta o WCM com base em pilares, visando à essência da filosofia conforme mostrado na Figura 1.

\begin{tabular}{|c|c|c|}
\hline Itens & Pilares Operacionais & Pilares Gerenciais \\
\hline 1 & Segurança & Envolvimento da Gerência \\
\hline 2 & Desenvolvimento de Custos. & Clareza de Objetivos \\
\hline 3 & Melhoramento Focado & Cronograma e Plancjamento para o WCM \\
\hline 4 & Atividades Autônomas & $\begin{array}{l}\text { Alocaçâo de Pessous qualificadas para aireas } \\
\text { modelo }\end{array}$ \\
\hline 5 & Manutençẫo Planejada & Envolvinento da organizaçầo \\
\hline 6 & Controle da Qualidade & $\begin{array}{l}\text { Competência da organizaçào em direçầo à } \\
\text { melhoria }\end{array}$ \\
\hline 7 & Logística e Serviço ao Cliente & Tempo \& Budget \\
\hline 8 & $\begin{array}{l}\text { Gestâo Preventiva de } \\
\text { Equipamentos }\end{array}$ & Nivel de expansâo \\
\hline 9 & Desenvolvimento de Pexsoas & Nivel de detallhes \\
\hline 10 & Meio Ambiente & Motivaçâio dos operadore f \\
\hline
\end{tabular}

Figura 1: Pilares operativos e gerenciais do WCM (Fonte: Oliveira, 2009) 
Os pilares gerenciais indicam o comprometimento que as pessoas e a organização devem demonstrar durante a aplicação do modelo para auxiliar o atendimento dos objetivos dos pilares operativos. Os pilares operativos representam os aspectos relacionados à produção sobre os quais se estruturam uma Manufatura de Classe Mundial. (CORTEZ, 2010). A metodologia é desenvolvida pelo aprofundamento das dez principais áreas da produção chamados de Pilares Técnicos (cada um com 7 passos de implantação), como ilustrado pela Figura 2.
Os três primeiros passos visam corrigir problemas após a sua ocorrência e precisam da intervenção de especialistas; os dois passos seguintes têm um caráter preventivo e podem ser feitos por uma intervenção individual: o próprio trabalhador inspeciona o trabalho; e os dois últimos passos representam a situação em que há uma antecipação ao surgimento dos problemas, que é feito pela intervenção de times.

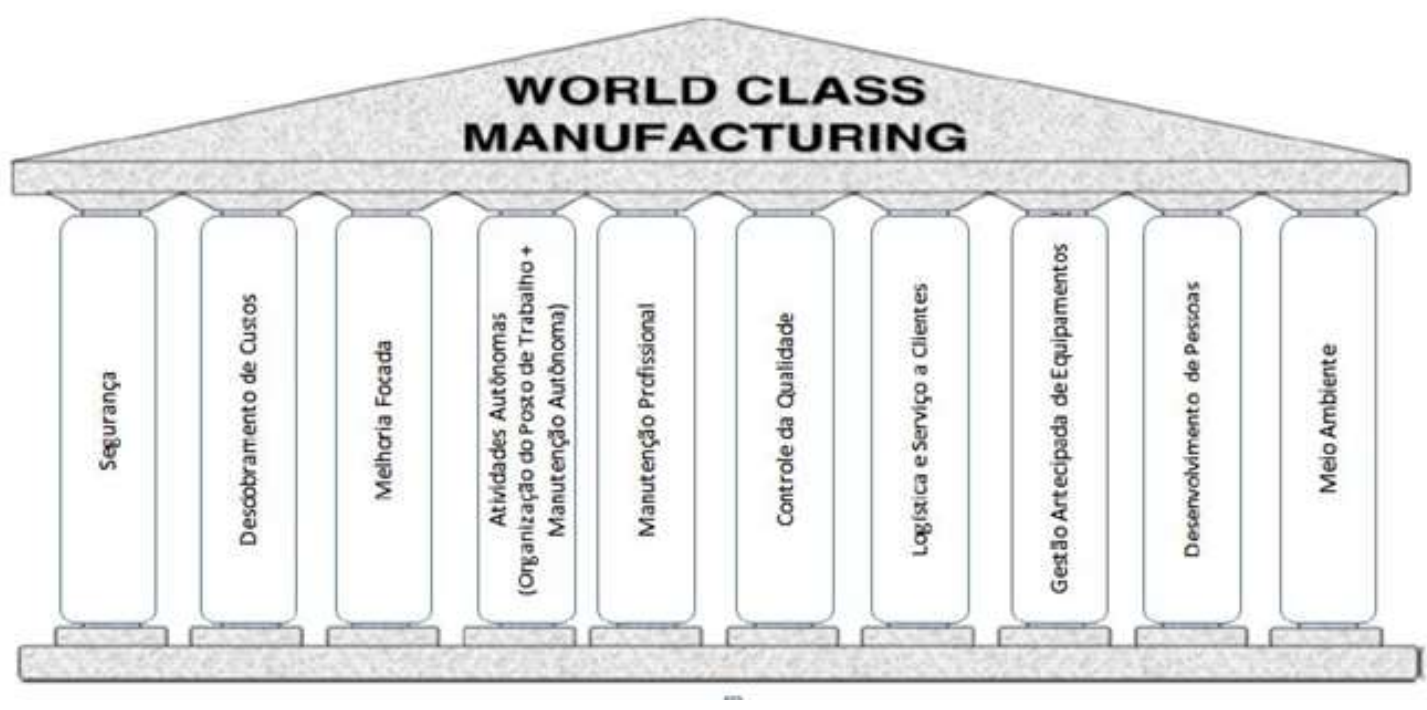

Figura 2 : Pilares do WCM (Fonte: Palucha 2012)

Para Yamashina (2007) o primeiro pilar "segurança" tem como propósito melhorar o ambiente de trabalho, trabalhando com a integridade física e psíquica do operador tornando-o menos propício às condições e atitudes inseguras analisando e eliminando as causas, desenvolvendo uma atitude preventiva, evitando assim os acidentes, ou quase acidentes . Para tal, é necessário atuar por meio de procedimentos sistêmicos, visando à prevenção de acidentes, por meio de observações, análise e eliminação de causas que propiciaram um acidente ou um quase acidente no local de trabalho.

Para Yamashina (2007), o pilar "desdobramentos de custo" é a bussola do WCM, pois norteia todos os outros pilares em transformar as perdas em custo, quantificandoas em medidas mensuráveis, como hora parada de máquina em unidade financeira, energia, refugos, falta de material, identificando qual o tipo de perda será atacada. Isso só é possível porque há uma comparação das perdas com as suas causas e origens. Depois de toda implementação de melhoria esse pilar avalia a economia obtida.

Yamashina (2000) afirma que caminho correto para se alcançarem resultados nesse pilar é por meio de dados confiáveis, isto é, somente assim é possível escolher as áreas para estudar e realizar monitoramento dos dados, de modo que se dê para comprovar a eficiência das ações realizadas na área.
- O pilar "melhoria focada" está direcionado a suprimir grandes perdas apontadas no pilar desdobramentos de custos, que depois de identificadas o pilar escolhe quais pilares que terão mais atenção por parte da gerência, e na orientação técnica sobre quais ferramentas e metodologias devem ser aplicadas para determinado tipo de problema. Esse pilar tem como premissa de não se limitar a fazer uma ação de contenção, mas sim investigar a causa raiz do problema e atacá-la para que não ocorra mais. (YAMASHINA, 2007).

- O pilar "manutenção autônoma e organização dos postos de trabalho". O pilar "manutenção autônoma" trabalha com a eficiência global do equipamento tem por objetivo prevenir os problemas dos equipamentos e as pequenas paradas quando acontecem devido à falta de manutenção das condições de base dos maquinários. Yamashina (2007) esclarece que a manutenção autônoma é de extrema importância para o WCM, já que os operadores podem executar trabalhos essenciais nos equipamentos que colaborarão com a manutenção e a preservação das máquinas ajudando assim em melhorias do produto, processo e equipamento. 
- O pilar "organização do posto de trabalho", trabalha para melhorar a eficiência e a produtividade do setor produtivo, eliminando as atividades que não geram valor ao produto, como por exemplo: se um funcionário vai buscar um produto em outro setor distante, na fábrica, gasta muito tempo para fazer tal atividade, há agregação de valor e menos desperdício de tempo se houvesse alocação do estoque para perto da linha. Este pilar desenvolve melhorias para que toda ferramenta fique em uma posição confortável para o operador, implantando a ergonomia e segurança do trabalho. (YAMASHINA, 2007)

- O pilar "manutenção profissional" abrange as atividades finalizadas com a construção de um sistema de manutenção capaz de reduzir a zero as quebras de máquinas, atuando na análise de avarias, as micro paradas dos equipamentos, aumentando o ciclo de vida das máquinas por meio de práticas de manutenção baseadas na capacidade de prorrogar a vida dos componentes (manutenção corretiva e preventiva). Este pilar tem atuação junto ao pilar de Manutenção Autônoma restaurando as condições básicas do equipamento e planejando a manutenção preventiva (YAMASHINA, 2007).

- O pilar "logística" é conhecido por gerir o fluxo produtivo em conjunto com o sistema de produção para garantir a satisfação dos clientes com menor lead time (tempo de entrega) e menor custo. Ou seja, tem por finalidade, produzir um fluxo eficiente por meio de análises de variáveis envolvidas na cadeia produtiva, diminuindo estoques, movimentações e transporte de materiais e também a possibilidade de danos aos produtos, além de trabalhar com toda cadeia logística de cliente e fornecedor. (YAMASHINA, 2000) Para Yamashina (2007), é necessária uma interligação entre os pilares para que os objetivos do pilar "logística" aconteçam realmente, já que a produção e o setor de vendas têm certa interdependência, a qual influencia diretamente sobre a logística.

- O pilar "gestão preventiva de equipamentos" tem como objetivo melhorar a competitividade das máquinas por meio da previsão de problemas que surgem nos equipamentos e garantir na aquisição de um equipamento novo, que a empresa deva comprar uma máquina que seja igual ou superior a que já está instalada na fábrica. Isso pode ser feito incluindo no projeto das máquinas todo o conhecimento e experiência vivida nas antigas. Sua função é aumentar o ciclo de vida dos equipamentos e desenvolver projetos em conjunto com os pilares de manutenção autônoma e profissional e integrar fornecedores.
(YAMASHIMA 2000). A fim de alcançar a qualidade elevada, custos mínimos, lead time de projeto reduzido, maior flexibilidade, segurança, facilidade de operações, confiabilidade, facilidade de manutenção, é fundamental a participação das pessoas envolvidas no gerenciamento, fornecimento e operadores das máquinas (YAMASHINA, 2007).

- O pilar "gestão de pessoas" é premissa para a implantação do WCM no que diz respeito ao desenvolvimento das competências das pessoas. Isso se deve ao fato de que, na metodologia WCM, a execução dos métodos e técnicas, bem como os resultados, dependem das pessoas. O pilar se baseia na avaliação dos problemas relacionados com competência, na formação para preencher essa deficiência e, por fim, na administração dos caminhos de aprendizagem. De acordo com Yamashina (2007), cabe a esse pilar desenvolver e motivar pessoas, reduzindo os erros humanos e trabalhar em conjunto com o pilar de segurança diminuindo os atos inseguros. Esse pilar identifica e organiza treinamento das ferramentas necessárias para os grupos de projetos para desenvolvimento de melhorias nos equipamentos.

- O pilar "ambiental" tem como propósito a melhoria contínua do local de trabalho ou do ambiente produtivo, mais especificamente a redução do consumo de energia e o uso de energias alternativas, promovendo a conscientização ambiental mediante o envolvimento com normas e regulamentos ambientais. O foco é dado na minimização dos impactos ambientais por meio de perdas individualizadas e ações contra o desperdício.

- O pilar "controle de qualidade", tem por objetivo fabricar produtos sem qualquer tipo de defeito, por meio da pesquisa aprimorada da capacidade e controle do processo. Para tal, realiza mudanças essenciais na lógica de controle de qualidade, isto é, atua não só nos controles e deliberações, mas também na perspectiva interna do processo produtivo, analisando as causas da má qualidade para, enfim, saná-las. Segundo Cortez, ET al (2010), este pilar trabalha para garantir a satisfação do cliente, atuando na conscientização dos operadores e na importância da qualidade na atividade de cada processo e seus atos. Além de diminuir as reclamações dos clientes através da análise de todos os defeitos de qualidade e reduzir o tempo entre a ocorrência do defeito, detecção e correção. 
Segundo Yamashina (2007), a integração desses pilares contribui, de forma eficaz, na redução das perdas que não agregam valor ao processo produtivo, elevando assim a empresa a níveis mundiais de manufatura.

Os resultados da implementação são avaliados através de auditorias que pontuam (de 0 a 10 ) cada um dos pilares, estabelecendo a atual condição da empresa quanto ao WCM. Plantas com mais de 50 pontos são certificadas com Medalha de Bronze; mais de 60 pontos, Medalha de Prata; mais de 70 pontos, Medalha de Ouro; e mais de 85 pontos a planta é classificada como Manufatura em Word Class. Em resumo, para uma empresa atingir o nível World Class, a metodologia influencia em todos os processos produtivos e logísticos, suportando-os com um sistema de auditoria e medindo seus indicadores principais (MIDOR, 2012) . Para o presente trabalho foi desenvolvido uma nova estrutura de pilares, conforme orientação do professor orientador experiente em avaliar a aplicação deste método, para ampliar a visão estratégica e analisar mais detalhadamente a metodologia WCM conforme mostrado na Tabela 1.

\begin{tabular}{|c|l|}
\hline Item & \multicolumn{1}{|c|}{ PRÁTICAS DE GESTÃo } \\
\hline 1 & 5 S \\
\hline 2 & 6 Sigma \\
\hline 3 & Sistema Toyota de Podução (STP) \\
\hline 4 & Sistema de Gestão da Qualidade (ISO 9001) \\
\hline 5 & Sistema de Gestão Ambiental (ISO 14001) \\
\hline 6 & $\begin{array}{l}\text { Sistema de Gestão da Segurança e Saúde } \\
\text { Ocupacional (OHSAS 18001) }\end{array}$ \\
\hline 7 & Sistema de Manutenção Produtiva Total (TPM) \\
\hline 8 & Sistema de Controle de Qualidade Total (TQC) \\
\hline 9 & Sistema de Gestão de Riscos (ISO 31000) \\
\hline 10 & Sistema de Desdobramento de Custos \\
\hline 11 & Sistema de Gestão de Energia (ISO 51000) \\
\hline 12 & Sistema de Gestão de Logistica \\
\hline 13 & Sistema de Controle de Processo (CEP) \\
\hline
\end{tabular}

Tabela 1: Nova estrutura de pilares do WCM (Fonte: Elaborada pela autora)

\section{Método}

A pesquisa é um instrumento pelo qual a investigação do problema proposto é viabilizada a fim de que os objetivos traçados sejam atingidos. Portanto, tendo em vista a abordagem deste trabalho, optou-se por realizar uma pesquisa de natureza indutiva, por meio de amostra de Empresas Pernambucanas que utilizam a WCM como Modelo de Gestão.

Para Vieira (2002) e Malhotra (2006), a pesquisa descritiva objetiva conhecer e interpretar a realidade, por meio da observação, descrição, classificação e interpretação de fenômenos, sem nela interferir para modificá-la. Conforme Vieira (2002), as pesquisas descritivas podem se interessar pelas relações entre variáveis e, dessa forma, aproximar-se das pesquisas experimentais. A pesquisa descritiva expõe as características de determinada população ou fenômeno, mas não tem o compromisso de explicar os fenômenos que descreve, embora sirva de base para tal explicação. Segundo Gil (2007), as pesquisas exploratórias são aquelas que possuem como objetivo principal o desenvolvimento ou esclarecimento de conceitos, propiciando estudos posteriores advindos de formulações de problemas mais precisos ou hipóteses pesquisáveis.

O trabalho foi desenvolvido através dos preceitos do estudo exploratório, por meio de uma pesquisa bibliográfica, desenvolvida a partir de material já elaborado, constituído de livros e artigos científicos e a elaboração de um questionário de pesquisa constituído com as partes da metodologia WCM em estudo através da respostas das empresas. Depois da elaboração do questionário foi realizada a entrevista com as empresas selecionadas a partir de ligações telefônicas e contatos via e-mail. Após o levantamento de todas as informações importantes. Com todos os dados disponíveis foram realizados gráficos e tabelas para saber realmente qual a situação das empresas estudadas evidenciando como esta a implantação do WCM nas empresas da região Nordeste.

Esta seção tem como objetivo apresentar os dados levantados durante o desenvolvimento da pesquisa. Primeiramente foram definidas as empresas do Estado de Pernambuco que buscam maior competitividade com novas tecnologias e soluções inovadoras através da implementação da metodologia do WCM que seriam pesquisadas no trabalho. Após o levantamento da pesquisa, por meio de telefonema e tratado pessoalmente com o Gerente de Produção ou o Representante da Direção - RD, foram estratificados os resultados e montada uma tabela, conforme Tabela 2, com as 20 empresas e os 13 itens presentes na metodologia WCM. Na tabela 1 mostra como está à aplicação da metodologia nas empresas da região Nordeste separando as empresas por grupos de atuação. Sendo Grupo 1 - Alimentos, Grupo 2 - Bebidas, Grupo 3 Bens de Consumo, Grupo 4 - Metal mecânica, Grupo 5 Petróleo, Grupo 6 - Automobilística, Grupo 7 - Cimentos, Grupo 8 - Energia, Grupo 9 - Gases Industriais, Grupo 10 - Resinas e Grupo 11 - Saneamento. Na tabela 1 também percebe-se uma coerência nos resultados, pois todas as empresas do Grupo 5 apresentaram as mesmas respostas devido às empresas terem a mesma governança.

Em seguida pesquisei o contato das empresas e realizei a consulta com o responsável da área de gestão ou qualidade para indicar quais itens da pesquisa estão presentes em suas empresas ajudando na melhoria continua. Com os dados tabulados surgiram gráficos para melhor representar como estão as empresas diante da metodologia WCM. 


\begin{tabular}{|c|c|c|c|c|c|c|c|c|c|c|c|c|c|c|c|c|c|c|c|c|c|c|}
\hline \multirow[b]{2}{*}{ then } & \multirow[b]{2}{*}{ PAITCAS DECESTAD } & \multicolumn{6}{|c|}{ 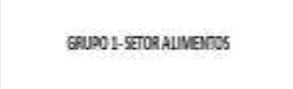 } & \multicolumn{2}{|c|}{$\begin{array}{l}\text { Grupo:- } \\
\text { stros:anat5 }\end{array}$} & \multicolumn{2}{|c|}{ 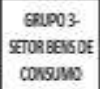 } & \multicolumn{2}{|c|}{$\begin{array}{l}\text { GPLOL- } \\
\text { प्रTORNER } \\
\text { MEcinch }\end{array}$} & \multicolumn{2}{|c|}{$\begin{array}{l}\text { gave 5- } \\
\text { SERz: } \\
\text { PETríco }\end{array}$} & \multirow{2}{*}{ 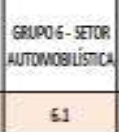 } & \multirow{2}{*}{ 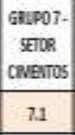 } & \multirow{2}{*}{\begin{tabular}{|c|}
$\begin{array}{c}\text { grupes- } \\
\text { ses } \\
\text { Bebsa }\end{array}$ \\
81 \\
\end{tabular}} & \multirow{2}{*}{ 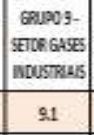 } & \multirow{2}{*}{ 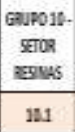 } & \multirow{2}{*}{ 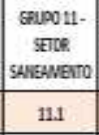 } & \multirow{2}{*}{ 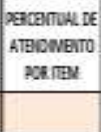 } \\
\hline & & 11 & 12 & 23 & 14 & 15 & 16 & 2.1 & 2.2 & 3.1 & 32 & 41 & 42 & 5.1 & 5.2 & & & & & & & \\
\hline 1 & 55 & $x$ & $x$ & 1 & 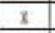 & 1 & $x$ & $x$ & $x$ & & 1 & $x$ & 1 & & & $x$ & $x$ & & & $x$ & $\mathrm{I}$ & $75,2 \mathrm{Bm}$ \\
\hline 2 & ESTgra & & & & $x$ & & & & $x$ & & & & & & & 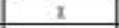 & & & & & & $15,5 \mathrm{sh}$ \\
\hline 3 & Sistema Toysts de Podugia (IIt) & & $x$ & I & $x$ & & $x$ & $x$ & $x$ & $\mathrm{I}$ & I & $x$ & I & & & $x$ & & & & $\mathrm{I}$ & $\mathrm{I}$ & $65,8 \mathrm{~h}$ \\
\hline 4 & 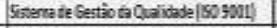 & $x$ & $x$ & 1 & 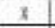 & 1 & $x$ & $x$ & $x$ & $\mathrm{t}$ & 1 & $x$ & & $x$ & 1 & $\mathrm{I}$ & $\mathrm{I}$ & 1 & $x$ & $\mathrm{x}$ & $\mathrm{I}$ & 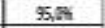 \\
\hline 5 & 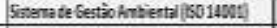 & $x$ & $x$ & 1 & 3 & 1 & $x$ & $x$ & $x$ & $\mathrm{t}$ & $\mathrm{I}$ & $x$ & 1 & $\mathrm{x}$ & 1 & $x$ & $x$ & 1 & $x$ & $x$ & $\mathrm{I}$ & 100,06 \\
\hline 5 & 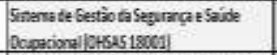 & $x$ & & I & $x$ & 1 & $x$ & $x$ & $x$ & $\mathrm{I}$ & I & & & $x$ & 1 & $x$ & $\bar{x}$ & 1 & $x$ & $\mathrm{x}$ & & 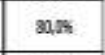 \\
\hline 7 & 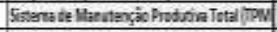 & $x$ & $x$ & 1 & $x$ & & & & $x$ & 5 & 1 & $x$ & 1 & & & $x$ & & 1 & & $\mathrm{~s}$ & 1 & $65, \mathrm{Mh}$ \\
\hline 8 & 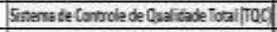 & $x$ & $x$ & 1 & $x$ & 1 & $\underline{x}$ & $x$ & $\underline{x}$ & 1 & 1 & $x$ & 1 & & & $x$ & & 1 & & 1 & 1 & 80,05 \\
\hline 3 & Sisterno te Gestio de Fiscos $|5031000|$ & & & & $x$ & & & & $x$ & & & & & & & $x$ & $x$ & 1 & $x$ & & & $30,0 \mathrm{~m}$ \\
\hline 10 & Gistamb fe Destabanertn de Cutrs & & & & $x$ & & & & $\mathrm{~A}$ & & & & & & & $\mathrm{I}$ & & & & & & $15,5 \mathrm{~m}$ \\
\hline 11 & Sisternate Getio de Enerģa| $5051000 \mid$ & & & & $x$ & & & & & & & & 1 & $x$ & 1 & $\mathrm{I}$ & & $i$ & & & 1 & $35,0 \mathrm{Kh}$ \\
\hline 12 & Sintanate Gestio de Log̣itica & & & I & & & $\underline{x}$ & $x$ & & & & & & $x$ & 1 & & $x$ & 1 & $x$ & & & $50,5 \mathrm{si}$ \\
\hline \multirow{2}{*}{\multicolumn{2}{|c|}{ 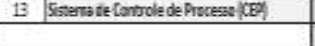 }} & $x$ & $x$ & $\mathrm{I}$ & $x$ & & $x$ & $x$ & $x$ & $\mathrm{I}$ & $\mathrm{I}$ & $x$ & & & & $x$ & & & & 1 & $\mathrm{I}$ & $65,0 \%$ \\
\hline & & & & & & & & & & & & & \multirow{3}{*}{\multicolumn{2}{|c|}{\begin{tabular}{|c|c|}
\multicolumn{2}{|l|}{} \\
31.58 & 38.55 \\
38.55
\end{tabular}}} & & & & & & & \\
\hline \multicolumn{2}{|r|}{ 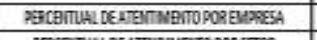 } & 58,34 & $53,9 \mathrm{~m}$ & 69,28 & 32.36 & $33.5 \mathrm{~h}$ & 61,58 & $61,5 \mathrm{~K}$ & Mes & 53,86 & 69,28 & \multirow{2}{*}{\multicolumn{2}{|c|}{$52,25[46,290$}} & & & 32,36 & $45.2 \%$ & $61.5 \%$ & 34.56 & 61.56 & 61,56 & \\
\hline \multicolumn{2}{|r|}{ PGECEITUAL DEATEISWEITO MOASTIOR } & \multicolumn{6}{|c|}{$615 \%$} & \multicolumn{2}{|c|}{$73.13 \%$} & \multicolumn{2}{|c|}{61,54} & & 50.066 & & & 92336 & $452 \%$ & 61,54 & $38.5 \%$ & $61,5 \%$ & 61.55 & \\
\hline
\end{tabular}

Figura 1 : Exemplo de como apresentar código dentro de uma figura - para centrar a legenda use o estilo figuraesq

\section{Resultados}

No Gráfico 1 pode-se observar que as práticas mais utilizadas consistem nos Sistemas de Gestão ISO 9001, ISO 14001 e OHSAS 18001, demonstrando que a busca pelo Sistema de Gestão Integrados - SGI é uma prática corriqueira nas empresas deste nível. Alie-se a este fato o sistema TQC. Essas metodologias foram as primeiras a surgirem na busca pela gestão da Qualidade nas organizações que queriam implementar um diferencial competitivo. Também clientes costumam exigir, de forma compulsória estas certificação para contratar seus fornecedores, fomentando a prática para implantação destas metodologias. Pelo Gráfico 1 verifica-se que o Sistema de Gestão Ambiental é utilizada por todas as empresas pes- quisadas representando $100 \%$ de implanta-ção e o Sistema menos utilizado é o Desdobramento de Custos representando apenas $15 \%$ (apenas três empresas pesquisadas utilizam este sistema de gestão) representan-do uma aplicação muito baixa. Este ato é notório no Brasil e no Mundo, em que o refinamento da gestão de custo não existe. Neste gráfico também se verifica que o Sistema de Gestão Ambiental (ISO 14001) superou o Sistema de Gestão da Qualidade (ISO 9001), sendo uma surpresa, deve-se ao fato que a regulamentação e exigência ambiental é compulsória para licenças de funcionamento e operação. Algo interessante e coerente é o fato das Empresas do setor de Petróleo terem o mesmo resultado e mesmas prática, deve-se ao fato de serem da mesma Governança corporativa. metodologia WCM.

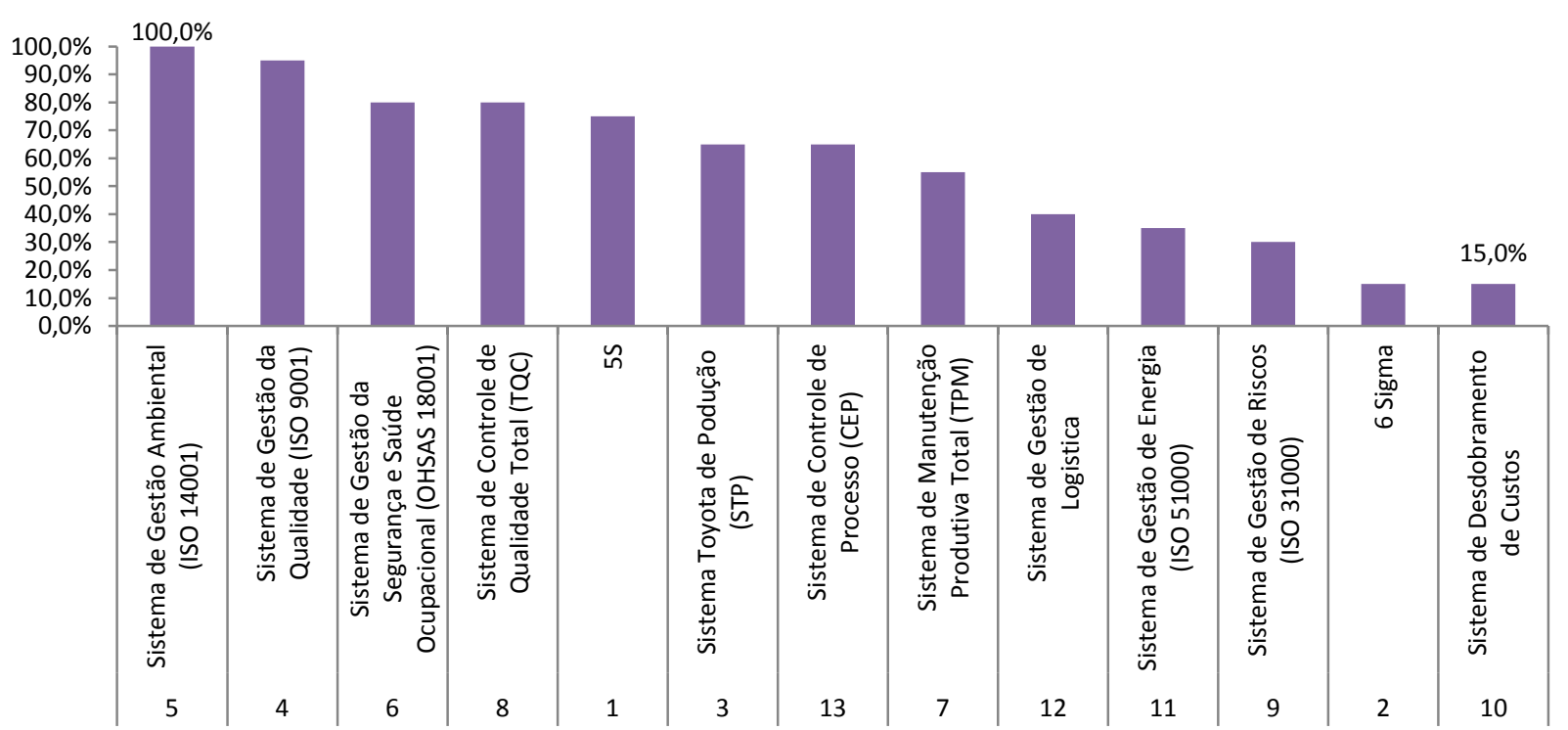

Gráfico 1 : Percentual de atendimento dos itens/práticas do modelo de gestão WCM nas empresas pesquisadas - Pareto 
No Gráfico 2, a seguir, percebe-se que o Grupo 6 é o que supera todos os outros grupos, mas é composto por uma única empresa automobilística pesquisada neste região, deve-se ao fato que é uma multinacional que adota em todas as filiais o WCM como Modelo de Gestão. Já no Grupo 2 as duas empresas pesquisadas são também multinacionais que adotam várias práticas de classe mundial. Vê-se também que a grande maioria dos grupos (7 em 11) estão acima de 50\% da implementação do WCM verificando-se que a busca por práticas de gestão de classe mundial faz parte dos objetivos estratégico das empresas pesquisadas.
No Gráfico 3 pode-se observar que existe três empresas que se destacam na implantação indicando que a metodologia está sendo implementada de forma intensa e as outras empresas estão em busca para obterem eficácia na sua implementação. Estas três empresas tem o ramo de atuação diferentes com isso ratifica-se que a metodologia realmente pode ser aplicada em todas os tipos de empresas, de qualquer ramo, independente dos seus processo e produtos e da cultura organizacional.

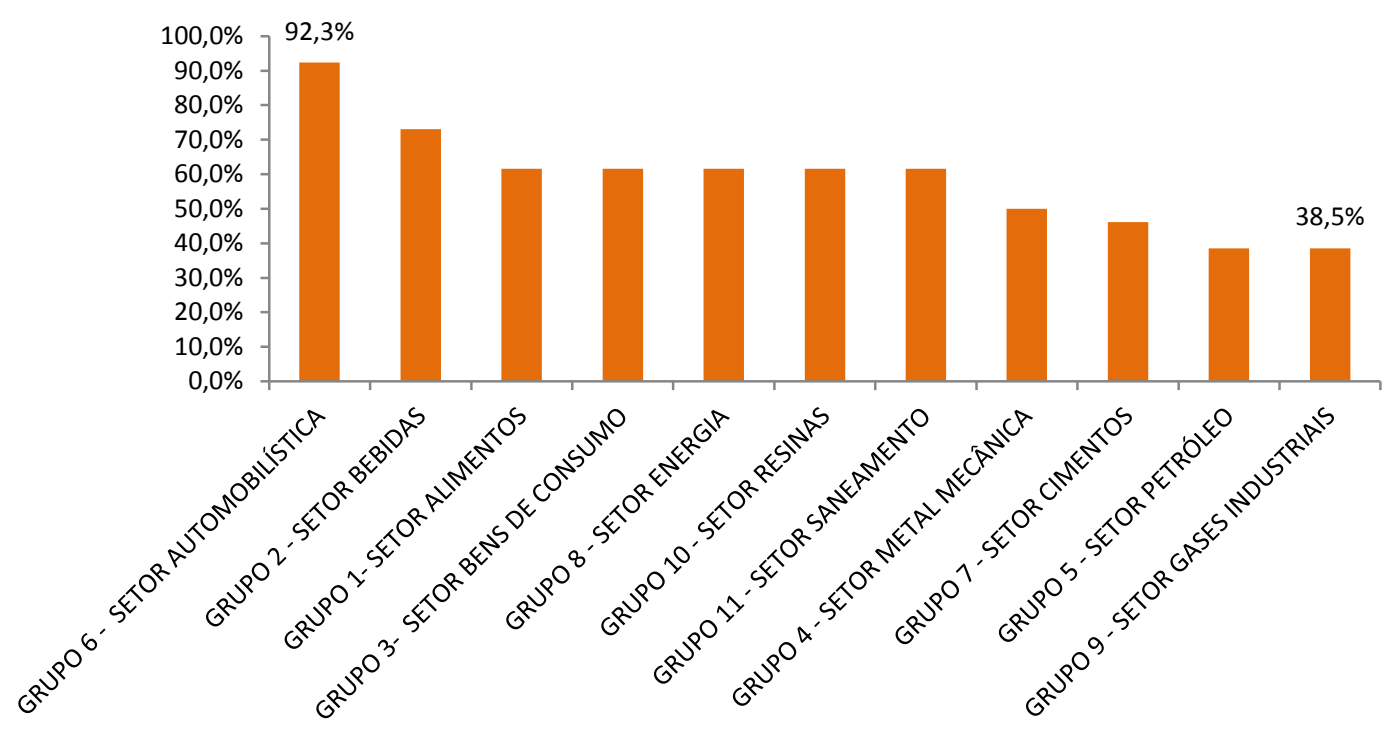

Gráfico 2: Percentual de atendimento por setor/grupo do modelo de gestão WCM nas empresas pesquisadas - Pareto Fonte: Elaborado pela autora

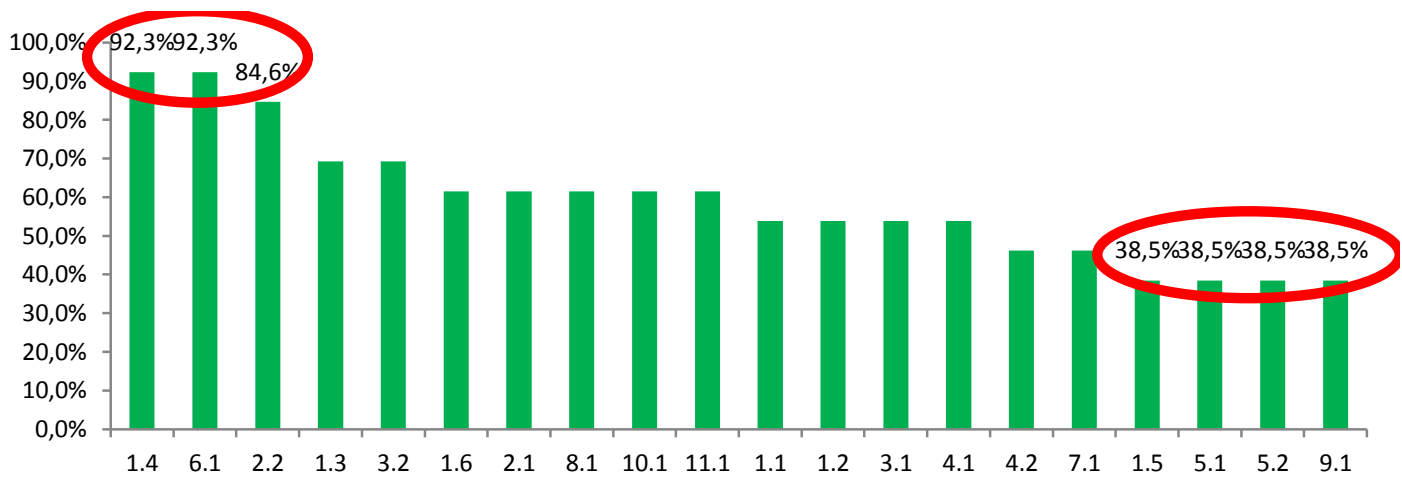

Gráfico 3: Percentual de atendimento das empresas pesquisadas no WCM Fonte: Elaborado pela autora 


\section{Resultados}

Pelo estudo apresentado conclui-se que a implementação do método WCM já está sendo utilizado pelas empresas, mas ainda falta muito para a obtenção de um índice de $100 \%$ das práticas, em particular no que se refere à Gestão de Custos. Das 20 (vinte) empresas pesquisadas apenas 03 (três) se destacam neste Modelo de Gestão. Estas empresas que se destacam na implementação do método atuam em setores diferentes de mercado, com isso percebe-se que a cultura do WCM pode ser aplicado em todas as empresas não importando o setor de atuação.

O SGI e TQC ficam destacados por serem as primeiras práticas de gestão a serem implementadas nas empresas para ajudar na gestão dos processos.

O Sistema de Gestão Ambiental ISO 14001 é utilizada por todas as empresas pesquisadas representando $100 \%$ de implantação e o sistema menos utilizado é o Desdobramento de Custos representando apenas $15 \%$, no caso, representando uma aplicação muito baixa deste sistema nas empresas pesquisadas. Também verifica-se que o Sistema de Gestão Ambiental (ISO 14001) superou o Sistema de Gestão da Qualidade (ISO 9001), não obstante este último sendo mais conhecido no mercado, pois as empresas estão sempre querendo melhorar sua competitividade em busca da sua sustentabilidade empresarial, o fato da ISO 14001 superar a ISO 9001 deve-se ao fato da elevação da exigência das legislações ambientais, pois em caso de não atendimento as empresas ficam sujeitas a multas elevadas. Já com o Sistema de Gestão da Qualidade (ISO 9001) não se adota multas, só a necessidade de atendimento as características técnicas mínimas do produto ou serviço.

Já o Sistema de Gestão de Logística representa apenas $40 \%$, não obstante este seja um influenciador dos custos dos produtos e serviços e as empresas necessitem de analisar e melhorar o impacto destes tanto internamente como externamente. Com o ambiente de recessão no país o Sistema de Gestão de Energia ISO 50001 deveria ser superior a $35 \%$, pois as empresas necessitam repensar seus custos e buscar sua redução, pois o impacto pode chegar em até $30 \%$ dos custos de produção.

O Sistema de Gestão de Riscos ISO 31000 pelo estudo representou apenas $30 \%$ de aplicação, mas acredita-se que irá mudar, pois a ISO 9001/2015 já exige uma melhor avaliação dos riscos estratégicos, táticos e operacionais e as empresas, que buscam práticas de classe mundial como WCM, não poderão deixar esta prática com percentual tão baixo, portanto o incremento deste Sistema de Gestão terá um tendência crescente nos próximos anos.
Por fim, o 6 Sigma representou somente $15 \%$. Isto se deve ao fato que o investimento em treinamento, desde funcionários até gerentes, nesta metodologia é muito alta e as empresas decidem não gastar tanto, mesmo com impactos em seus produtos e serviços.

Em relação ao desdobramento de custos percebe-se que as empresas brasileiras não dão atenção devida a este item, de forma refinada, pois se preocupam com a implantação dos Sistema de Gestão, mas continuam com deficiência nesta prática, não obstante seja o grande objetivo empresarial.

Neste ramo do estudo existem muitas oportunidades de melhoria, pois na metodologia WCM pelos dados apresentados existem muitas lacunas que ainda não foram exploradas. A exploração dessas lacunas pode melhorar a gestão da empresa para manter sempre competitiva e diferenciada no mercado no mercado de atuação

\section{Referências}

[1] CHIAVENATO, I. Introdução à teoria geral da administração. 4. ed., São Paulo: Makron Books, 1993.

[2] CORTEZ, P. R. L. Análise das Relações entre o Processo de Inovação na Engenharia de Produto e as Ferramentas do WCM: Estudo de Caso Em Uma Empresa do Setor Automobilístico. XXX ENGEP - Encontro Nacional de Engenharia de Produção. São Paulo. 2010.

[3] FELICE, Fábio; PETRILlO, Antonella; MONFREDA, Stanislao. Improving Operations Performance with World Class Manufacturing Technique: A Case in Automotive Industry. Intech, Cassino, Itália, v. 1, n. 3, mar. 2013. Disponível em: <www.intechopen.com>. Acesso em: 15 julho 2016.

[4] GAITHER; N. \& FRAIZER, G. Administração da Produção e Operações. $8^{\mathrm{a}}$ ed. São Paulo: Cengage Learning. 2002. 598 p.

[5] GIL, A.C. Métodos e Técnicas de Pesquisa Social. 5 ed. São Paulo: Atlas, 2007.

[6] MIDOR, Katarzyna. World Class Manufacturing - characteristics and implementation in an automotive enterprise. Scientific Journals Maritime University of Szczecin. Krynica Morska, 2012.

[7] MALHOTRA, Naresh K. Malhotra. Pesquisa de marketing: uma orientação aplicada Porto Alegre: Bookman, 2006.

[8] MARTINS, P. G. e LAUGENI, F. P. Administração da Produção. 2 ed. São Paulo: Editora 
Saraiva. 2005. 562 p.

[9] OHNO, Thaiichi. O Sistema Toyota de Produção - Além da Produção em larga escala.- Ed. Bookman. 1997.

[10] OLIVEIRA, D. P. Rebouças de Planejamento Estratégico: conceito, metodologia, práticas: 22. ed. 2.São Paulo, 2009.

[11] PADDOCK, B. Top management's: Guide to World Class Manufacturing. 1st ed. Kansas City: Buker, Inc., 1993. 83 p.

[12] PAŁUCHA, K. World Class Manufacturing model in production management. Archives of Materials Science and Engineering, Zabrze, dez. 2012.

[13] PASSARELLA, M. Benchmarking Production System. 2007.

[14] RUBRICH, L.; \& WATSON, M. Implementing World Class Manufacturing. 2 ed. Fort Wayne, Indiana, 2004. 437p.

[15] SCHONBERGER, R. J. World Class Manufacturing: The Lessons of Simplicity Applied.

New York, New York. 1986. 253 p.

[16] SLACK. N. et al. Administração da Produção. 2.ed. São Paulo: Atlas, 2002. 747 p.

[17] VIEIRA, V. A. As tipologias, variações e características da pesquisa de marketing. Revista da FAE, Curitiba. 2002.

[18] WIREMAN, T. Total Productive Maintenance An American Approach, Industrial Press Inc., New York, NY. 1990.

[19] WOMACK, James P.; JONES, Daniel T. A mentalidade enxuta nas empresas Lean Thinking: Elimine o desperdício e crie riqueza. 5. ed. Rio de Janeiro: Campus, 2006.

[20] YAMASHINA, Hajime. Challenge to worldclass manufacturing. Institute Journal of Quality \& Relability Management, Kyoto, 2000. 